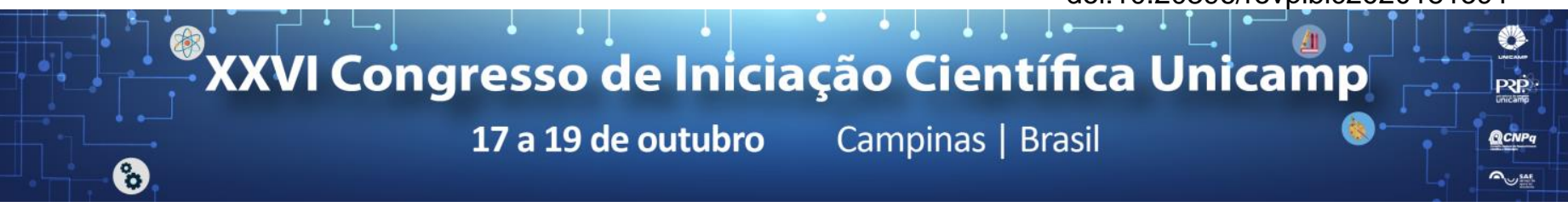

\title{
Determinação dos metabólitos secundários do fungo Neopestalotiopsis sp.
}

\author{
Yasmim R. Lopes*, José Eraldo do N. Fontes, José Matheus C. Bonatto, Anita J. Marsaioli.
}

\section{Resumo}

Foram realizados estudos de triagens enzimáticas em coleção de microorganismos disponíveis no laboratório LabioChem para a detecção de MAO (monoamino oxidases) e TAS (transaminases). Dentre esses microorganismos, a atividade enzimática se mostrou intensa sobretudo pelo fungo Neopestalotiopsis sp. Levando isso em consideração, o presente relatório apresenta um estudo dos metabólitos secundários produzidos pelo fungo em questão cultivado em três diferentes meios: uva, tomate e morango. Resultados analisados indicam a ocorrência de alelopatia entre fungo e planta através da producação de ácido benzoico.

\section{Palavras-chave:}

Metabólitos secundários, Neopestalotiopsos sp., alelopatia.

\section{Introdução}

O estudo dos metabolitos secundários desempenha um papel importante para desvendar as interações das plantas com o meio ambiente ${ }^{1}$.

A comunicação entre os organismos vivos através de biomoléculas é denominado de Alelopatia, parte da ciencia que estuda a influência de um indivíduo sobre outro. $^{2}$

Estudos relacionados ao Neopestalotiopsis sp. gira em torno das ações patógenas do mesmo em plantas de diferentes espécies, como uva ${ }^{3}$, tomate ${ }^{4}$, morango ${ }^{5}$. Como também das atividades enzimáticas, principalmente no que se refere a MAO (Monoamina Oxidase) e TAS (Transaminase) que transformam enantiosseletivamente cetonas e aminas em compostos de interesse. ${ }^{6}$

Sendo assim, o objetivo deste trabalho é determinar os metabólitos secundários do fungo em questão e relacionar com o efeito alelopático já relatado na literatura.

\section{Resultados e Discussão}

Autoclavou-se as soluções A e B (apresentadas na Tabela 1), em $116 \stackrel{\circ}{\circ}$ e $121^{\circ} \mathrm{C}$, respectivamente. Ajustou-se o pH para 7.0, em seguida misturou-se as duas soluções. Separou-se em 6 erlenmeyers, $300 \mathrm{~mL}$ de meio para cada. Preparou-se $30 \mathrm{~mL}$ de pré-inóculo. O crescimento do fungo em extrato de tomate se deu por 6 dias e 8 dias respectivamente.

Tabela 1. Composição do meio de cultura utilizando o extrato de tomate, uva e morango (separadamente)

\begin{tabular}{|c|c|}
\hline Solução $\mathrm{A}$ & Solução B \\
\hline $200.0 \mathrm{~g}$ de leite em pó & $\begin{array}{c}200 \mathrm{~mL} \text { de suco de tomate ou } \\
\text { uva ou morango }\end{array}$ \\
\hline $1600 \mathrm{~mL}$ de água & $10,0 \mathrm{~g}$ de extrato de levedura \\
\hline & $200 \mathrm{~mL}$ de água \\
\hline
\end{tabular}

Logo após, utilizou-se $500 \mathrm{~mL}$ de acetato de etila para a realização da extração em um funil de separação de $2 \mathrm{~L}$, adicionou-se também $1 \mathrm{~mL}$ de $\mathrm{NaOH}(6 \mathrm{M})$.

Após a extração, as amostras foram injetadas no CG/EM para análise dos metabólitos. A Figura 1 mostra os espectros obtidos do cultivo do fungo nos 3 meios diferentes (tomate, morango e uva).

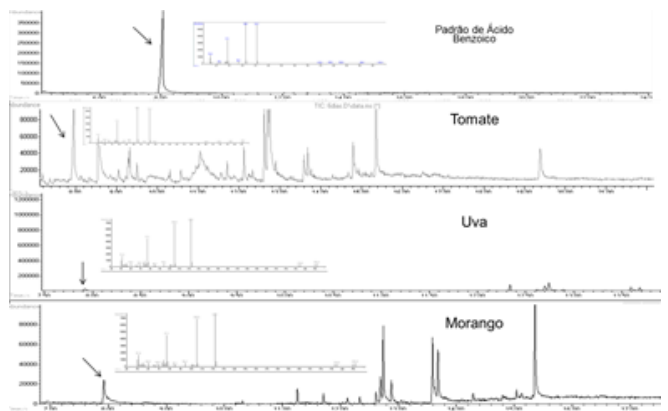

Figura 1. Cromatogramas dos extratos brutos do fungo cultivado em meios baseados em sucos do tomate, uva e morango, respectivamente.

Dentre os metabólitos identificados, o ácido benzoico foi destacado pois não estava presente no experimento controle (extrato do Neopestalotiopsis sp) e destacava-se nos extratos com do Neopestalotiopsis cultivado com os sucos de morango, uva ou tomate, acima a mencionados. Um padrão do ácido benzoico foi injetado nas mesmas condições das análises anteriores e apresentou mesmo tempo de retenção e espectro. Portanto pode-se constatar que o composto de interesse, é o Ácido Benzoico, um composto relacionado a processos alelopáticos, que envolvem compostos do metabolismo secundários que interferem em vários processos metabólicos de plantas. O Ácido Benzoico, entre outros compostos fenólicos, atua diretamente na diminuição do tamanho e da biomassa das plantas já citadas.

\section{Conclusões}

Dessa maneira, como demonstrado pelos resultados obtidos e pesquisas realizadas constatou-se o processo alelopático entre o fungo Neopestalotiopsis sp. e as plantas do tomate, morango e uva.

\section{Agradecimentos}

Os autores agradecem ao CerSUSChem-FAPESP 2014/50249-8 CNPQ e ao IQ/Unicamp pelo apoio financeiro e estrutura necessária para realização do referido trabalho.

\footnotetext{
1http://www.oleosessenciais.org/metabolismo-secundario-das-plantas/

${ }^{2}$ Ferreira, A. G; Aquila, M. E. A; R. Bras. Fisiol. Veg. 2000, 12, 175.

${ }^{3}$ Jayawardena, R. J. et al. Fungal Biology, 2015, 119, 5, 348.

${ }^{4}$ Ayoubi, N; Pari, S. S. Jounal of Plant Diseases and Protection, 2016, 123,267.

${ }^{5}$ Ayoubi, N; Soleimani, M. J. Curr Microbiol, 2016, 72, 239.

${ }^{6}$ Costa, J.H. et al. Applied Macrobiology and Biotechnology, 2017, 101, 6061.
} 